\title{
Skeletal mechanism modelling of $n$-heptane/oxygen laminar coflow flame structure at pressures
}

\author{
Sen $\mathrm{Li}^{*}$, Xiaolin $\mathrm{Wei}^{1}$ \\ State Key Laboratory of High Temperature Gas Dynamics, Institute of Mechanics, Chinese Academy of Sciences, No. 15 Beisihuanxi Road, Beijing 100190, China
}

\section{H I G H L I G H T S}

- The skeletal mechanism of $n$-heptane combustion was developed and validated.

- $n$-Heptane/oxygen were investigated by the developed skeletal mechanism.

- The maximum soot volume fraction increases as $f_{v, \max } \propto P^{2}$ with increasing pressure.

- $n$-Heptane/oxygen flame height decreased with increasing pressure.

\section{A R T I C L E I N F O}

\section{Article history:}

Received 20 February 2015

Received in revised form 30 August 2015

Accepted 7 September 2015

Available online 15 September 2015

\section{Keywords:}

Skeletal mechanism

n-Heptane

Flame structure

Soot

\begin{abstract}
A B S T R A C T
A skeletal reaction mechanism of $n$-heptane combustion is developed and validated. The axisymmetric laminar co-flow diffusion flames of $n$-heptane/oxygen are simulated using the skeletal mechanism at elevated pressure, and the chemical reaction paths in three reaction zones of flame are presented. The $n$-heptane/oxygen flame height decreases from 8.8 to $5.6 \mathrm{~mm}$ with the increase of pressure from 0.1 to $2 \mathrm{MPa}$, and the Roper's formulation is not expected for the prediction of $n$-heptane/oxygen flame height The maximum volume fraction of soot increases with pressure as $f_{v, \max } \propto P^{2}$. The ratio of flame height to soot oxidation length of the $n$-heptane/oxygen flames is close to unity (1.037-1.121).
\end{abstract}

(c) 2015 Elsevier Ltd. All rights reserved.

\section{Introduction}

Although high-pressure combustion of hydrocarbon fuels is widely applied in most practical transportation and propulsion devices (e.g., aircraft gas turbines, diesel engines and rocket engines) [1-6], our understanding of high-pressure combustion is relatively limited. One of the major causes is the non-trivial nature of tractable high-pressure combustion experiments $[2,3]$ and simulations $[1,4]$. In the practical high-pressure devices, the high level of intermittency due to turbulent motion and relatively short residence time involved in these flames is not always suitable for experimental measurements of combustion $[1,4]$. Compared to the turbulent combustion in practical combustion devices, a laminar coflow diffusion flame has the simplest configuration from which the interactions between flow field and reactions can be readily modified and studied.

\footnotetext{
* Corresponding author. Tel.: +86 10 82544231, +86 10 82544366; fax: +86 10 82544231.

E-mail address: lisen@imechac.cn (S. Li).

1 Tel.: +861082544366
}

Recently, some researchers have performed high-pressure combustion experiments of gaseous hydrocarbon fuels/air laminar diffusion flames at pressures above $1 \mathrm{MPa}$ [7-10]. High-pressure hydrocarbon/oxygen combustion can effectively enhance the combustion intensity and reduce the size of combustion devices [11]. However, there is not much information on the high-pressure hydrocarbon/oxygen characteristics in open literature [1]. Most of the research done at atmospheric pressure is related to oxyfuel combustion applications [12], and the experiment and simulation of high-pressure oxy-fuel combustion is done by using oxygen-enriched air as oxidizer [1].

$n$-Heptane $\left(n-\mathrm{C}_{7} \mathrm{H}_{16}\right)$ is an important component of gasoline, diesel and kerosene, and it is thought to be a good surrogate fuel to represent liquid transportation fuel [7,13-16]. The combustion characteristics of $n$-heptane/oxygen are very important for the design of niche aerospace applications such as liquid propellant rocket engines. The accurate understanding of coflow flame structure is crucial to investigate the highly complex reaction nature of $n$-heptane/oxygen combustion. However, the experimental research of high-pressure laminar hydrocarbon/oxygen flame is always held back by the complications in designing experimental 
apparatus and operating instruments that require accessibility for intrusive and non-intrusive measurement techniques [17], from which it is difficult to obtain detailed information for combustion analysis. Although the numerical simulation of combustion coupled with the validated reaction mechanism is a useful tool to predict the hydrocarbon/oxygen combustion characteristics, the detailed reaction mechanism of $n$-heptane combustion contains too many species and reactions to be used in practical combustion simulations. In order to reduce time and cost of simulation, the development of a skeletal mechanism based on the detailed mechanism is needed.

The main objective of the research is to investigate the nheptane/oxygen combustion characteristics of laminar coflow diffusion flame by combustion numerical simulation coupled with the developed and validated skeletal reaction mechanism. The pressure effect on the flame structure is discussed, and the reaction paths of pollutant formation (polycyclic aromatic hydrocarbons (PAHs) and soot) and combustible species oxidation are analyzed.

\section{Skeletal mechanism formulation}

Wang and coworkers [18] developed $n$-heptane-PAHs mechanism including $n$-heptane mechanism (131 reactions, 40 species) and PAHs mechanism (139 reactions, 20 species) to predict soot formation. Since the detailed $n$-heptane-PAHs mechanism contains too many species and reactions, it is much too costly to use the mechanism to couple with computational fluid dynamic (CFD) codes. In the following simulation of $n$-heptane/oxygen laminar coflow flame, the CFD simulation is done by ANSYS Fluent code software which only allows a maximum of 500 reactions and 50 species. In the study, the skeletal mechanism of $n$-heptane-PAHs is formed from Wang's mechanism.

\subsection{Mechanism reduction method}

The reduction methods of skeletal mechanism include directed relation graph (DRG) [19], directed relation graph with error propagation (DRGEP) [20], principal component analysis (PCA) and so on [21]. Nagy and Turanyi [22] reviewed the various methods for the identification of unimportant species. In the study, PCA is based on sensitivity analysis to simplify detailed $n$-heptane-PAHs mechanism. PCA is an eigenvalue-eigenvector analysis of the matrix $S^{\mathrm{T}} S$, where $S$ is the sensitivity matrix of the normalized sensitivity coefficients and $S^{\mathrm{T}}$ is its transpose [23]. The eigenvalues provide an absolute measure of the significance of some parts in the mechanism, the magnitude of coefficients in the eigenvector measures the significance of reactions for a given eigenvalue, thus eigenvalues and eigenvectors measure the significance of reactions in the overall mechanism. In the study, PCA is used to provide the objective criterion for selecting a minimum reaction set. The skeletal mechanism only includes the principal components and the corresponding reactions. The kinetic information inherent in the elements of the normalized rate sensitivity matrix $S$ can be extracted by PCA method. The normalized sensitivity coefficient $\left(S_{i j}\right)$ at a number of time steps $t_{l}$ is defined as follows

$S_{i j}\left(t_{l}\right)=\frac{\partial \ln c_{i}\left(t_{l}\right)}{\partial \ln k_{j}\left(t_{l}\right)}$

where $c_{i}$ is the concentration of species $i, k_{j}$ is the pre-exponential factor $(A)$ in the Arrhenius equation of reaction $j$, and $S_{i j}\left(t_{l}\right)$ represents the fractional change in the concentration $c_{i}$ caused by a fractional change of the parameter $k_{j}$. As reported by Vajda et al. [24], PCA proceeds via a systematic methodology for dividing the reaction space into important and unimportant portions, which is based on the response function $Q(k)$ to quantify the variations in the set of $m$ input rate coefficient parameters, $\mathbf{k}=\left(k_{1}, k_{2}, \ldots, k_{m}\right)$, where $\mathbf{k}^{\mathbf{0}}=\left(k_{1}^{0}, k_{2}^{0}, \ldots, k_{m}{ }^{0}\right)$ is the nominal value.

$Q(k)=\sum_{l=1}^{q} \sum_{j=1}^{m} \frac{c_{i}\left(t_{l}, k_{j}\right)-c_{i}\left(t_{l}, k_{j}^{0}\right)}{c_{i}\left(t_{l}, k_{j}^{0}\right)}$

With $\alpha_{j}=\ln c_{j}$, the classical Gauss approximation gives

$Q(\mathbf{k})=\Delta \alpha^{\mathrm{T}} S^{\mathrm{T}} S \Delta \alpha$

where $\Delta \alpha_{j}=\alpha_{j}-\alpha_{j}^{0}$ and $\Delta \alpha=\left(\Delta \alpha_{1}, \Delta \alpha_{2}, \Delta \alpha_{3}, \ldots, \Delta \alpha_{m}\right)$. The importance of reactions can be determined by performing eigenvalueeigenvector analysis of matrix $S^{\mathrm{T}} S$. The important reactions are characterized by large eigenvalues. The response function is the sum of the squared errors for each species at different time steps. The detailed steps of mechanism reduction are described in Ref. [23]. By providing the user-specified squared errors for each species at different time steps for the response function $(Q(\mathbf{k}))$, unnecessary reactions can be identified. When the reduced mechanism includes 50 species and 241 reactions (see Appendix A) which meets the requirements of coupling simulation with ANSYS Fluent code software, the difference between detailed and temporary reduced mechanisms is $23 \%$ for ignition time at a given operating conditions in the study (see Section 2.2.1). In the study of $n$-heptane/oxygen laminar coflow flame structure at elevated pressure, $\mathrm{N}_{2}$ is used to the dilution gas of $n$-heptane fuel flow. In the simulation, species of $\mathrm{N}$ and $\mathrm{N}_{2}$ are respectively included in the element block and the species block, even though they are not included in the combustion reactions.

\subsection{Validation of the skeletal mechanism}

\subsubsection{Validation of ignition delay time}

Ignition delay time $\left(\tau_{\text {ign }}\right)$ is predicted by the skeletal reaction mechanism, which can reflect the combustion characteristics of hydrocarbon fuels. The predicted results are compared and validated by Hartmann's experimental data [25]. The ignition delay time of $n$-heptane/air mixtures was measured in shock tube when the equivalence ratio of $n$-heptane/air, pressure and temperature were $1.0,40 \pm 2$ bar, $700-1200 \mathrm{~K}$, respectively. The prediction of ignition delay time is based on an adiabatic constant-volume homogeneous reactor model with the skeletal mechanism. The ignition delay time is calculated by SENKIN program and extracted based on a steepest-increase criterion of $\mathrm{OH}$ mole fraction vs. time curve. The measured and simulated ignition delay times are shown in Fig. 1, the $S$-shaped curve indicates a negative temperature coefficient (NTC) regime, and the simulated results have a good agreement with the measured data in the wide temperature range at high pressure.

\subsubsection{Validation of free radical, $P A H$ and soot formation}

The $n$-heptane pyrolysis and PAHs/soot formation are important to investigate the $n$-heptane combustion characteristics. Oliveira et al. [26] qualitatively measured PAHs and quantitatively measured soot in $n$-heptane/air laminar coflow flame at atmospheric pressure. In order to validate the skeletal mechanism for flame structure prediction, the distributions of PAHs and soot in the $n$-heptane/air laminar coflow flame described in Ref. [26] are simulated.

\section{(A) The validation experiment setup}

The experimental burner setup was described in Refs. [26,27]. The burner was a coflow burner with a fuel tube (inner diameter of $4 \mathrm{~mm}$ and outer diameter of $6 \mathrm{~mm}$ ) and a coflow (inner diameter of $50 \mathrm{~mm}$ and a height of $100 \mathrm{~mm}$ ). The flow rates of $n$-heptane, carrier gas flow (air) and coflow oxidizer (air) were respectively 


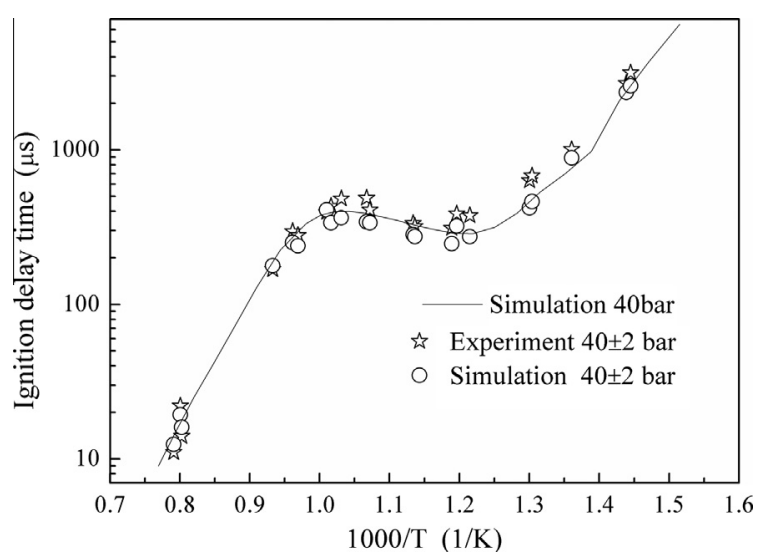

Fig. 1. Comparison of the measured and simulated ignition delay times of $n$-heptane/air mixtures when the equivalence ratio of $n$-heptane/air is 1 .

$4.5 \mathrm{~g} / \mathrm{h}, 18.4 \mathrm{~g} / \mathrm{h}$ and $25.92 \mathrm{~g} / \mathrm{min}$, and the $n$-heptane vapor was maintained at $373 \mathrm{~K}$. Laser-Induced Fluorescence (LIF) was used to detect PAHs by $266 \mathrm{~nm}$ excitation [28], and Laser-Induced Incandescence (LII) was employed for measuring the soot volume fraction $\left(f_{v}\right)$ by $1064 \mathrm{~nm}$ excitation.

\section{(B) Numerical model}

The transport equations of mass, momentum, energy, gas-phase species, soot mass fraction, soot number density, and radiation intensity are closed with the equation of state and appropriate boundary condition in axisymmetric cylindrical coordinates [4]. The effect of buoyancy is accounted by retaining the gravity term in the momentum equation. The skeletal mechanism of $n$ heptane-PAHs is coupled with ANSYS Fluent code software to simulate the laminar coflow diffusion flame. The detailed algorithm is described in Ref. [4], and the SIMPLE numerical algorithm is used to treat the pressure and velocity coupling.

In Moss-Brookes-Hall soot formation model of high hydrocarbon fuel [29], soot inception is based on the formation of 2ringed and 3-ringed aromatics $\left(\mathrm{C}_{10} \mathrm{H}_{7}\right.$ and $\left.\mathrm{C}_{14} \mathrm{H}_{10}\right)$ by acetylene, benzene and phenyl radicals as follows:

$2 \mathrm{C}_{2} \mathrm{H}_{2}+\mathrm{C}_{6} \mathrm{H}_{5} \rightarrow \mathrm{C}_{10} \mathrm{H}_{7}+\mathrm{H}_{2}$
$\mathrm{C}_{2} \mathrm{H}_{2}+\mathrm{C}_{6} \mathrm{H}_{6}+\mathrm{C}_{6} \mathrm{H}_{5} \rightarrow \mathrm{C}_{14} \mathrm{H}_{10}+\mathrm{H}+\mathrm{H}_{2}$

In the soot model, the species of $\mathrm{C}_{2} \mathrm{H}_{2}, \mathrm{C}_{6} \mathrm{H}_{6}$ and $\mathrm{C}_{2} \mathrm{H}_{4}$ are considered as soot precursors and growth surface. The mass of an incipient soot particle (12 carbon atoms) is $144 \mathrm{~g} / \mathrm{mol}$, and the mean density of soot particle is $2 \mathrm{~g} / \mathrm{cm}^{3}$. The soot model solves the transport equations of the normalized radical nuclei, growth and oxidation [30].

Gas and soot radiations are modeled by the assumption of optically thin radiation transfer between a given fluid element (or soot) in the flame and the cold surroundings. It is assured that the only significant radiating gas species are $\mathrm{H}_{2} \mathrm{O}, \mathrm{CO}$ and $\mathrm{CO}_{2}$. By adopting an optically thin limit in which self-absorption of radiation is neglected [31], the net radiative flux loss term can be written as follows:

$Q_{\text {rad }}=-4 \sigma\left(T^{4}-T_{b}^{4}\right) \times\left(a_{g}+a_{s}\right)$

where $\sigma=5.669 \times 10^{-8} \mathrm{~W} / \mathrm{m}^{2} \mathrm{~K}^{4}, T$ is the local flame temperature, $T_{b}$ is the background temperature, and $a_{g}$ and $a_{s}$ are respectively the Planck mean absorption coefficients of gas and soot. $a_{\mathrm{g}}$ is expressed as follows:

$a_{g}=\sum_{i} P_{i} a_{P i}$ where $P_{i}$ is the partial pressure of species $i$ in atmosphere. The extinction coefficient $a_{P i}$ of species $i$ can be found from Refs. [32,33]. $a_{s}$ is expressed as follows [33]:

$a_{s}=1232.4 f_{v} \rho_{\text {soot }}[1+0.00048(T-2000)]$

where $f_{v}$ is the volume fraction of soot in flame, and $\rho_{\text {soot }}$ is soot density $\left(\mathrm{kg} / \mathrm{m}^{3}\right)$.

In the simulation of experimental chamber, the scheme grids of computing domain are shown in Fig. 2. The domain is modeled by a combination of (hexahedral) individually discretized numerical sub-grids, the grids are refined near nozzle zone, the total grids contain approximately 110,000 cells, and the minimum and maximum volumes are respectively $2 \times 10^{-12}$ and $3 \times 10^{-8} \mathrm{~m}^{3}$. The simulation time required for a case is about $15 \mathrm{~h}$ by using $8 \mathrm{CPU}$ cores.

\section{(C) The comparison of the measured and simulated results}

The qualitative measurement of PAHs and quantitative data of soot volume fraction $\left(f_{v}\right)$ were provided in Ref. [26]. Fig. 3 shows the simulated and measured results of PAHs and soot, where the high signal intensity of the measured PAHs corresponds to high concentration. PAHs and soot contours of the simulated and measured results are similar in shape (see Fig. 3(a) and (b)), where HAB is the height above the burner lip. Fig. 3(c) shows the simulated and measured concentration profiles of soot along the flame centerline. The simulated and measured maximum $f_{v}$ are respectively 0.094 and $0.0089 \mathrm{ppm}$, and the location of simulated peak-value soot along the flame centerline is roughly $2 \mathrm{~mm}$ taller than the experimental corresponding locations. The above discrepancy can be attributed to the difficulty of assigning the velocity profiles of the fuel and air streams at the burner exit surface in the simulation. In despite of above the slight discrepancy, the measured and simulated distribution shapes of PAHs and soot are similar, the simulated soot volume fraction $\left(f_{v}\right)$ is comparable to that of experiment, and these simulation results can qualitatively reproduce the $n$-heptane combustion experiment. Therefore, this validates that the skeletal mechanism can be used to simulate PAHs and soot formation.

\section{Simulation of $\boldsymbol{n}$-heptane/oxygen laminar coflow flame at elevated pressure}

In the simulation, as is mentioned above, the simulated coflow burner setup and the numerical model are described in Section 2.2. $\mathrm{N}_{2}$ gas replaces air as fuel carrier gas, and pure oxygen gas replaces air as coflow oxidizer. The flow rates of $n$-heptane, carrier gas flow $\left(\mathrm{N}_{2}\right)$ and coflow oxidizer $\left(\mathrm{O}_{2}\right)$ are respectively $4.5 \mathrm{~g} / \mathrm{h}, 18.4 \mathrm{~g} / \mathrm{h}$ and $28.6 \mathrm{~g} / \mathrm{min}$, the $n$-heptane vapor is maintained at $373 \mathrm{~K}$, and pressure varies from 0.1 to $2 \mathrm{MPa}$.

\subsection{Flame zone structure}

Flame shape is an important characteristic of laminar diffusion flames, and the shape can be profoundly affected by pressure and mixture diffusion. In the study, the flame surface is defined as the flame sheet where the stoichiometric ratio $(S R)$ of oxidizing species to combustible species is equal to 1 , and the flame height is the height above the burner lip (HAB) at which flame surface crosses the axis. Fig. 4 shows the flame zone structures at 0.1 and $2 \mathrm{MPa}$, and Fig. 5 presents the profiles of the main species along the flame centerline at $2 \mathrm{MPa}$.

Although the shape and size of each flame zone vary with pressure, the flame structures are similar at different pressure (see Fig. 4). The diffusion flame consists of the following three zones 


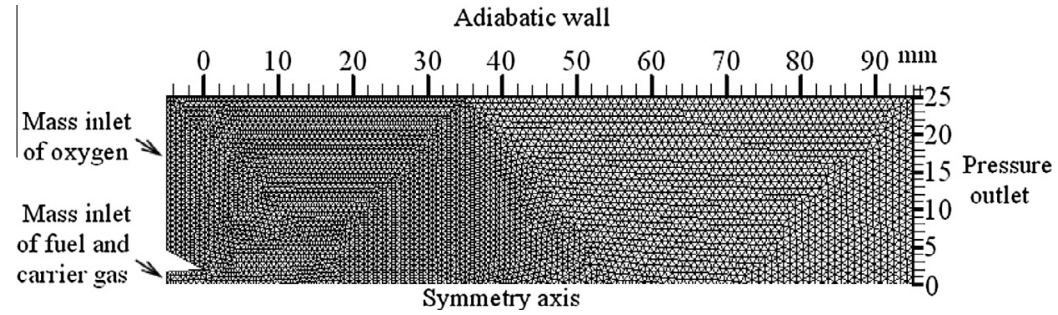

Fig. 2. Scheme grids of computing domain.

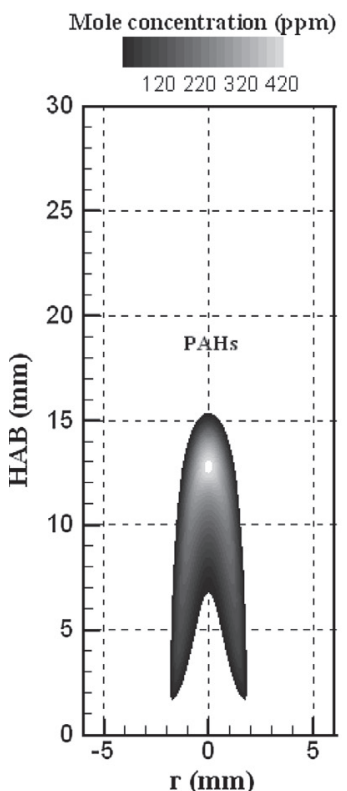

(a) Simulated concentration contours

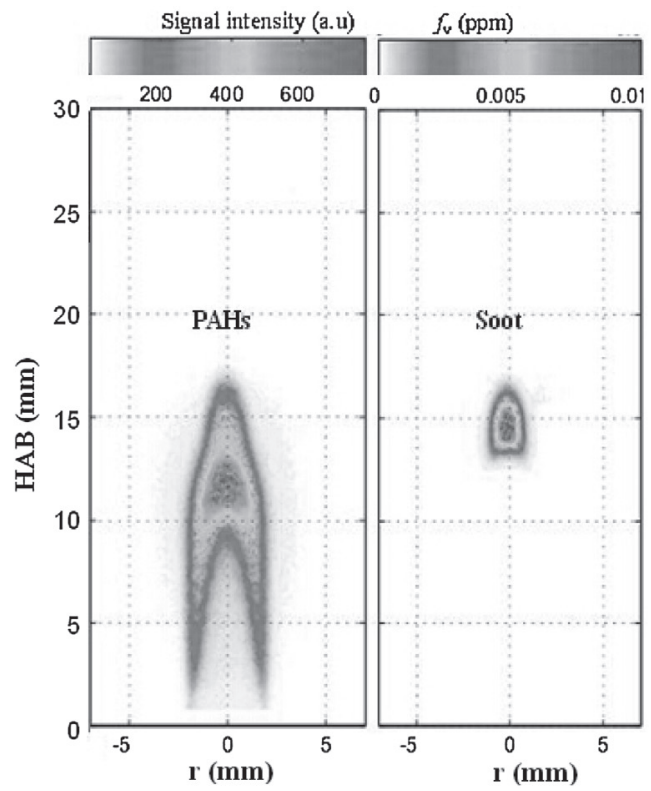

(b) Measured concentration contours [23]

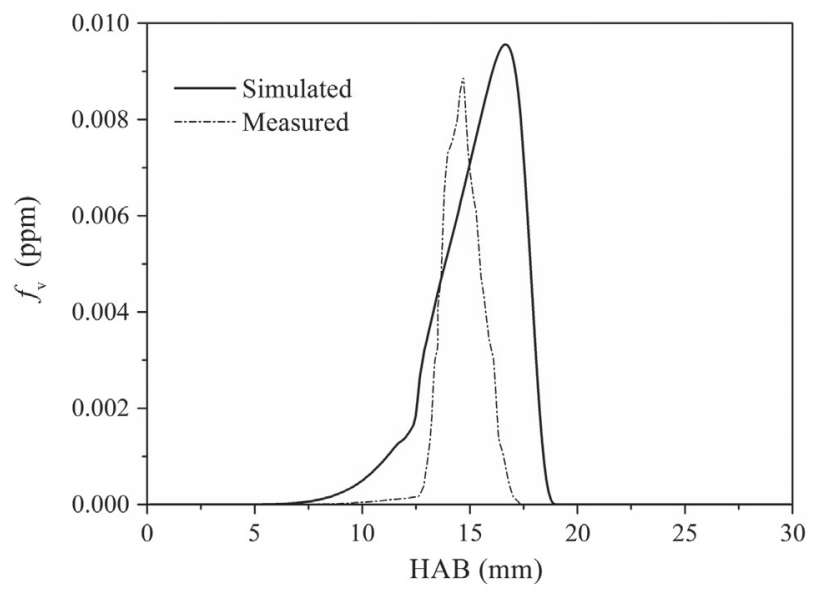

(c) Simulated and measured concentration profiles of soot along the flame centerline

Fig. 3. Simulated and measured PAHs/soot concentration distributions.

(as known from Figs. 4(b) and 5): fuel heating zone, fuel-rich reaction zone and oxidizer-rich reaction zone. In fuel heating zone, fuel $n-\mathrm{C}_{7} \mathrm{H}_{16}$ enters combustion chamber and is heated by diffusion and convection. As oxygen and fuel move towards flame reaction zone, the combustible species are heated and mixed in the reaction zone, and the flame surface is formed at any location where the fuel and oxidizer meet in the stoichiometric proportions where $S R$ is equal to 1 . The fuel-rich zone and oxidizer-rich zone are separated by the flame surface (see the black curve at $S R=1$ in Fig. 4). In fuel-rich zone, $n-\mathrm{C}_{7} \mathrm{H}_{16}$ is firstly decomposed into small molecule gases (e.g., $\mathrm{H}_{2}, \mathrm{CH}_{4}, \mathrm{C}_{2} \mathrm{H}_{2}, \mathrm{C}_{2} \mathrm{H}_{4}, \mathrm{C}_{2} \mathrm{H}_{6}, \mathrm{C}_{3} \mathrm{H}_{4}, \mathrm{C}_{3} \mathrm{H}_{6}$, etc.), and some pollutants (PAHs and soot) are formed, where the zone is luminous in the practical flame. In the oxidizer-rich zone, a large amount of $\mathrm{OH}$ radical is formed in high temperature condition; PAHs and soot 


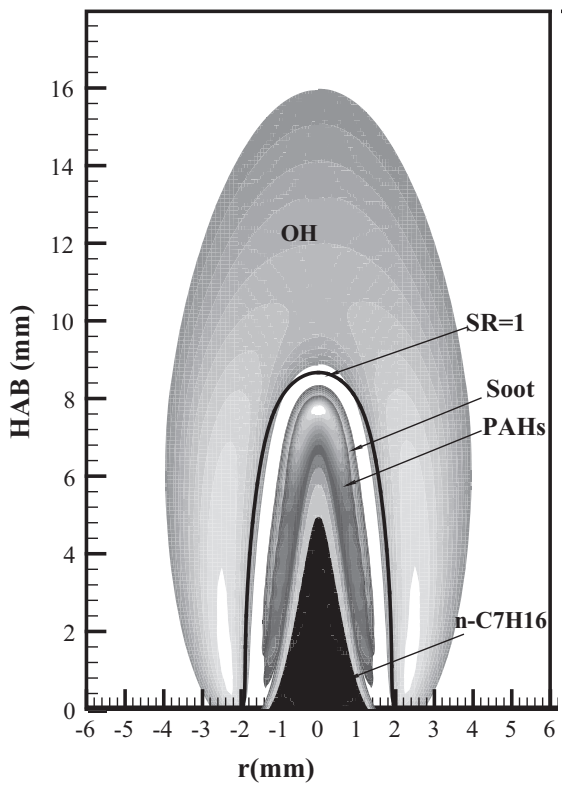

(a) $0.1 \mathrm{MPa}$

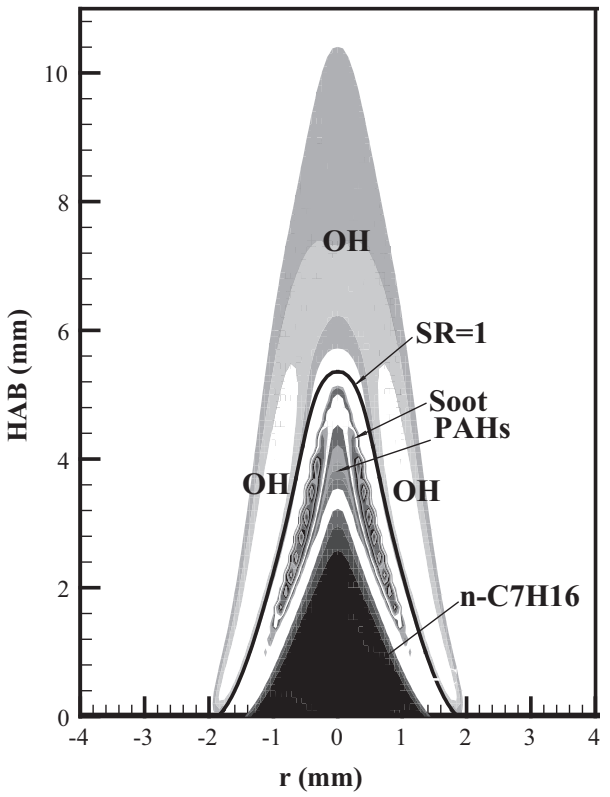

(b) $2 \mathrm{MPa}$

Fig. 4. Flame structures.

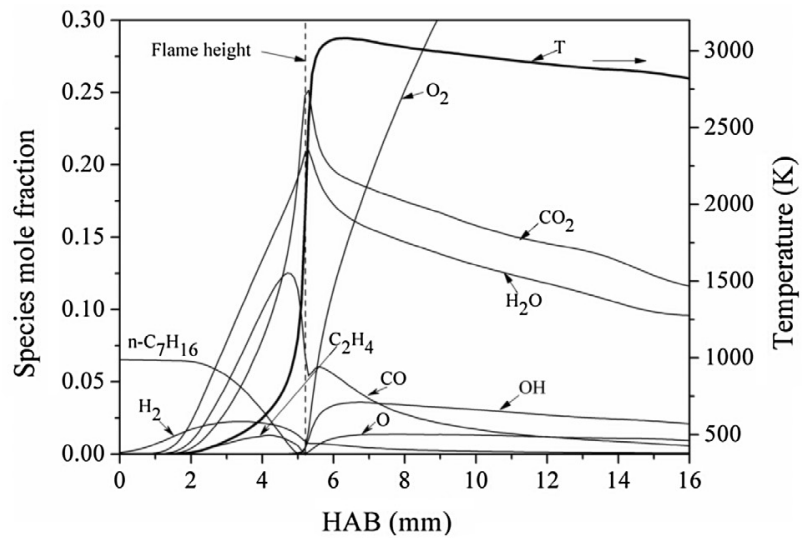

(a)

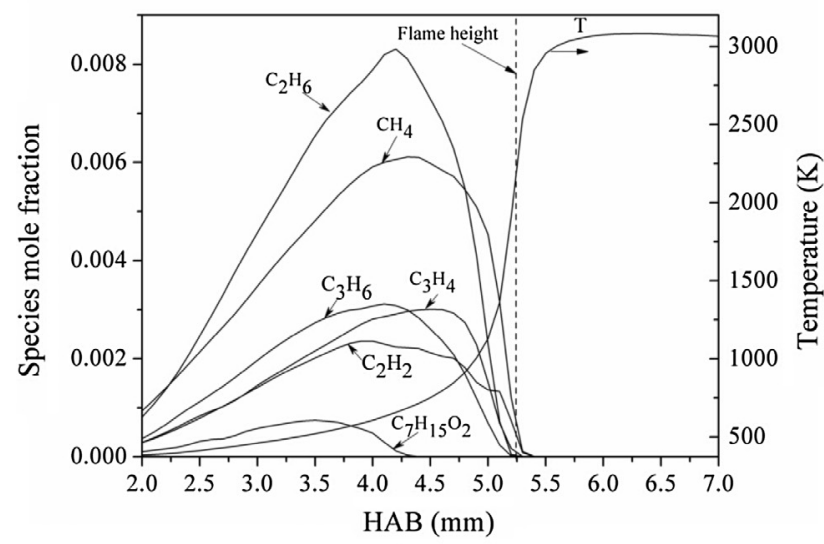

(b)

Fig. 5. The profiles of the main species in the flame centerline at $2 \mathrm{MPa}$.

are oxidized (see Figs. 4 and 5); these small molecule hydrocarbon species and carbon monoxide are burned; the reaction zone turns into a partially premixed flame where oxygen intensively penetrates into the flame zone (see Fig. 5(a)); the zone is mostly blue in the practical flame. At $0.1,0.5$ and $1 \mathrm{MPa}$, the profiles of main species are similar to those at $2 \mathrm{MPa}$ (see Fig. 5), and increasing pressure makes the peaks of species concentrations gradually approach burner exit.

\subsection{Reaction mechanism of each flame zone}

In the fuel-rich zone, fuel is heated and pyrolysed. In order to investigate the reaction mechanisms, the reaction pathway flux analysis is performed using MixMaster (a Python program that is part of the Cantera suite) [34]. The integral path analysis is based on a conserved scalar approach to reaction fluxes [34]. Since the reaction paths are similar at $0.1-2 \mathrm{MPa}$, Fig. 6 only illustrates the detailed reaction pathway diagram for C-containing species at 2 MPa (see Figs. 4(b) and 5), where the relative width of the arrows indicates pathway importance.

As known from Fig. 6, the $\mathrm{H}$-abstraction reactions are the dominant pathway. Firstly, $\mathrm{H}$ abstraction of $n$-heptane by $\mathrm{H}$ radical is

$n-\mathrm{C}_{7} \mathrm{H}_{16}+\mathrm{H} \rightarrow \mathrm{C}_{7} \mathrm{H}_{15}+\mathrm{H}_{2}$

and the $\mathrm{H}$-abstraction reaction is pressure independent [35]. The oxygen addition reaction of the low-temperature chemistry of $n$ heptane occurs:

$\mathrm{C}_{7} \mathrm{H}_{15}+\mathrm{O}_{2} \rightarrow \mathrm{C}_{7} \mathrm{H}_{15} \mathrm{O}_{2}$

At the meantime, the thermal decomposition reaction of $\mathrm{C}_{7} \mathrm{H}_{15}$ becomes important:

$\mathrm{C}_{7} \mathrm{H}_{15} \rightarrow \mathrm{C}_{2} \mathrm{H}_{4}+\mathrm{C}_{2} \mathrm{H}_{5}+\mathrm{C}_{3} \mathrm{H}_{6}$

$\mathrm{C}_{2} \mathrm{H}_{5}(+\mathrm{M}) \rightarrow \mathrm{C}_{2} \mathrm{H}_{4}+\mathrm{H}(+\mathrm{M})$

$\mathrm{C}_{2} \mathrm{H}_{4}+\mathrm{M} \rightarrow \mathrm{C}_{2} \mathrm{H}_{3}+\mathrm{H}+\mathrm{M}$

$\mathrm{C}_{3} \mathrm{H}_{6}+\mathrm{H} \rightarrow \mathrm{C}_{3} \mathrm{H}_{5}+\mathrm{H}_{2}$

Additionally, the H-addition reactions of $\mathrm{C}_{2} \mathrm{H}_{4}, \mathrm{C}_{2} \mathrm{H}_{5}$ and $\mathrm{C}_{3} \mathrm{H}_{6}$ occur when the concentration of $\mathrm{H}$ radical increases: 


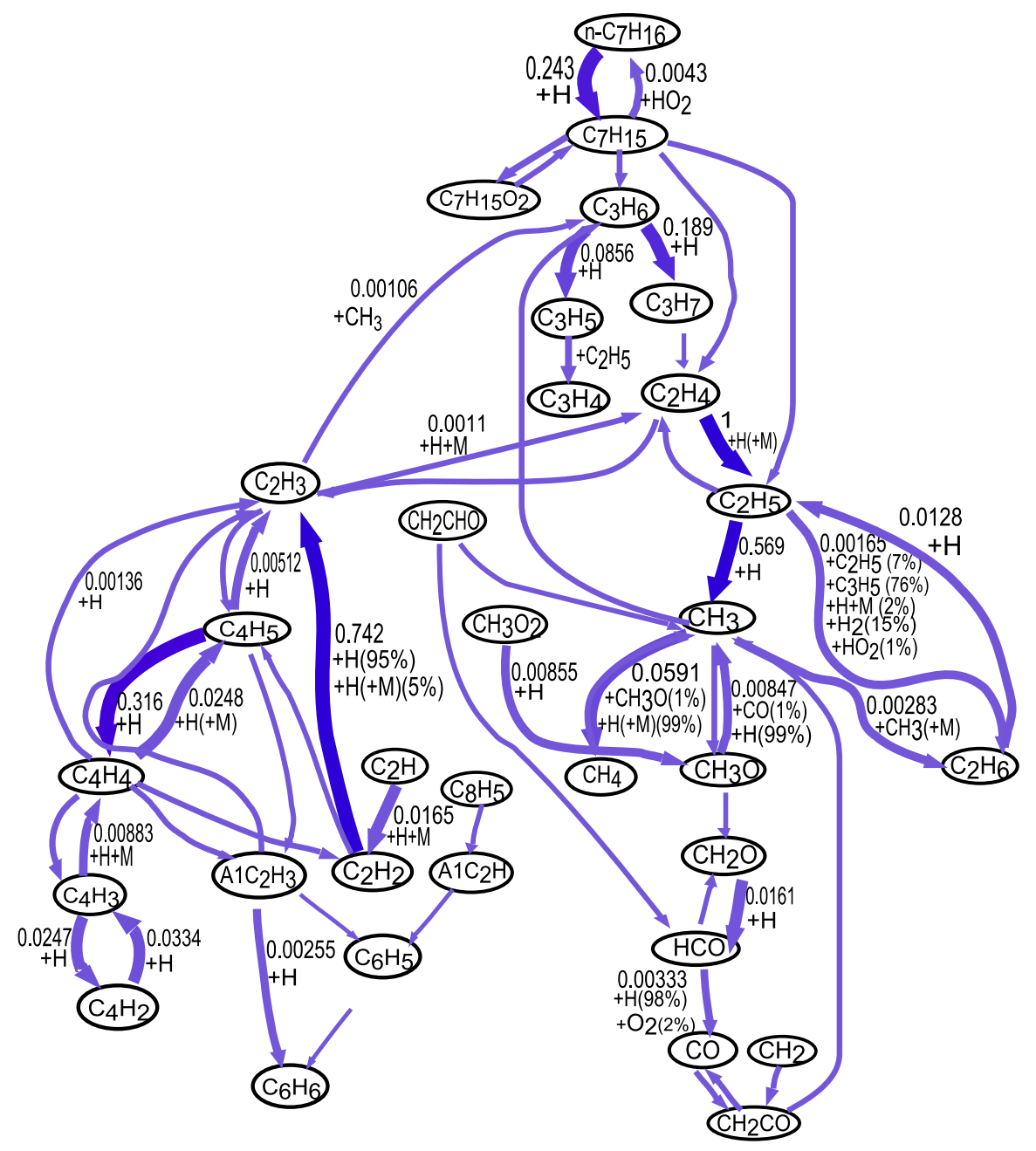

Fig. 6. Reaction pathway diagram for C-containing species at flame centerline $\mathrm{HAB}=3.5 \mathrm{~mm}$ at $2 \mathrm{MPa}$.

$\mathrm{C}_{2} \mathrm{H}_{4}+\mathrm{H}(+\mathrm{M}) \rightarrow \mathrm{C}_{2} \mathrm{H}_{5}(+\mathrm{M})$

$\mathrm{C}_{2} \mathrm{H}_{5}+\mathrm{H} \rightarrow 2 \mathrm{CH}_{3}$

$\mathrm{C}_{3} \mathrm{H}_{6}+\mathrm{H} \rightarrow \mathrm{C}_{3} \mathrm{H}_{7}$

$\mathrm{CH}_{3}+\mathrm{H}(+\mathrm{M}) \rightarrow \mathrm{CH}_{4}(+\mathrm{M})$

The main reaction paths of $\mathrm{C}_{2} \mathrm{H}_{6}$ are as follows:

$\mathrm{C}_{2} \mathrm{H}_{5}+\mathrm{C}_{3} \mathrm{H}_{5} \rightarrow \mathrm{C}_{2} \mathrm{H}_{6}+\mathrm{C}_{3} \mathrm{H}_{4}$

$\mathrm{CH}_{3}+\mathrm{CH}_{3}(+\mathrm{M}) \rightarrow \mathrm{C}_{2} \mathrm{H}_{6}(+\mathrm{M})$

In the soot model of Moss-Brookes-Hall, soot formation precursors include $\mathrm{C}_{2} \mathrm{H}_{2}, \mathrm{C}_{6} \mathrm{H}_{5}, \mathrm{C}_{6} \mathrm{H}_{6}$ and $\mathrm{C}_{2} \mathrm{H}_{4}$, and the formation reaction paths are presented in Fig. 7. The formation of the first aromatic ring is a key-point in soot formation. In the skeletal mechanism model, PAHs include $\mathrm{C}_{6} \mathrm{H}_{6}$ and $\mathrm{A} 2\left(\mathrm{C}_{10} \mathrm{H}_{8}\right)$. An aromatic ring $\left(\mathrm{C}_{6} \mathrm{H}_{6}\right.$ or $\left.\mathrm{C}_{6} \mathrm{H}_{5}\right)$ is the start point for the growth of a soot particle.

In the oxygen-rich zone with high temperature, there exists a large amount of oxidizing species $\left(\mathrm{O}_{2}, \mathrm{OH}\right.$ and $\mathrm{O}$ free radicals) which are main culprits and responsible for the destruction of the soot particle [36]. In the oxidizing atmosphere, soot, PAHs and light gases are decomposed and oxidized, and the combustion reaction paths are shown in Fig. 8.

\subsection{Pressure influence on flame height and temperature}

The effects of pressure on temperature distribution and the flame surface are presented in Fig. 9. With the increase of pressure from 0.1 to $2 \mathrm{MPa}$, the temperature peak value increases from 2848 to $3221 \mathrm{~K}$, the flame surface becomes progressively narrower, and flame height drops. Since the density of mixture in flame increases with the increase of pressure, the buoyancy becomes important and accelerates the flow of product gases in flame [4], and the streamlines move closer together to conserve mass and cause narrowing flame surface as the velocity increases [1] (see Fig. 9).

In the simulation, the $n$-heptane/oxygen flame height decreases from 8.8 to $5.6 \mathrm{~mm}$ with the increase of the pressure from 0.1 to $2 \mathrm{MPa}$. Joo and Gülder [1] demonstrated by experiments that the flame height of methane/oxygen flame was not observed to stay constant from 10 to $100 \mathrm{MPa}$, and the height steadily decreased as the pressure was increased to $5 \mathrm{MPa}$. The result of flame height variation of hydrocarbon/oxygen with pressure is different from that of hydrocarbon/air flame [37]. Gülder et al. [7,11] performed the experiments of methane/air and $n$-heptane/air coflow laminar flames, and these experiment results showed that: the flame height 

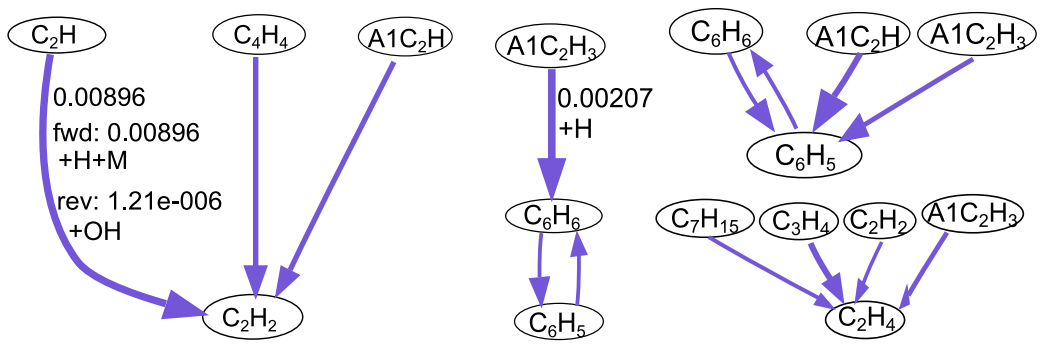

Fig. 7. Reaction paths of soot precursors $\left(\mathrm{AlC}_{2} \mathrm{H}\right.$ (phenyl acetylene, $\mathrm{C}_{6} \mathrm{H}_{5} \mathrm{C}_{2} \mathrm{H}$ ); $\mathrm{AlC}_{2} \mathrm{H}_{3}$ (phenylvinyl radical, $\mathrm{C}_{6} \mathrm{H}_{4} \mathrm{CH}=\mathrm{CH}_{2}$ )).

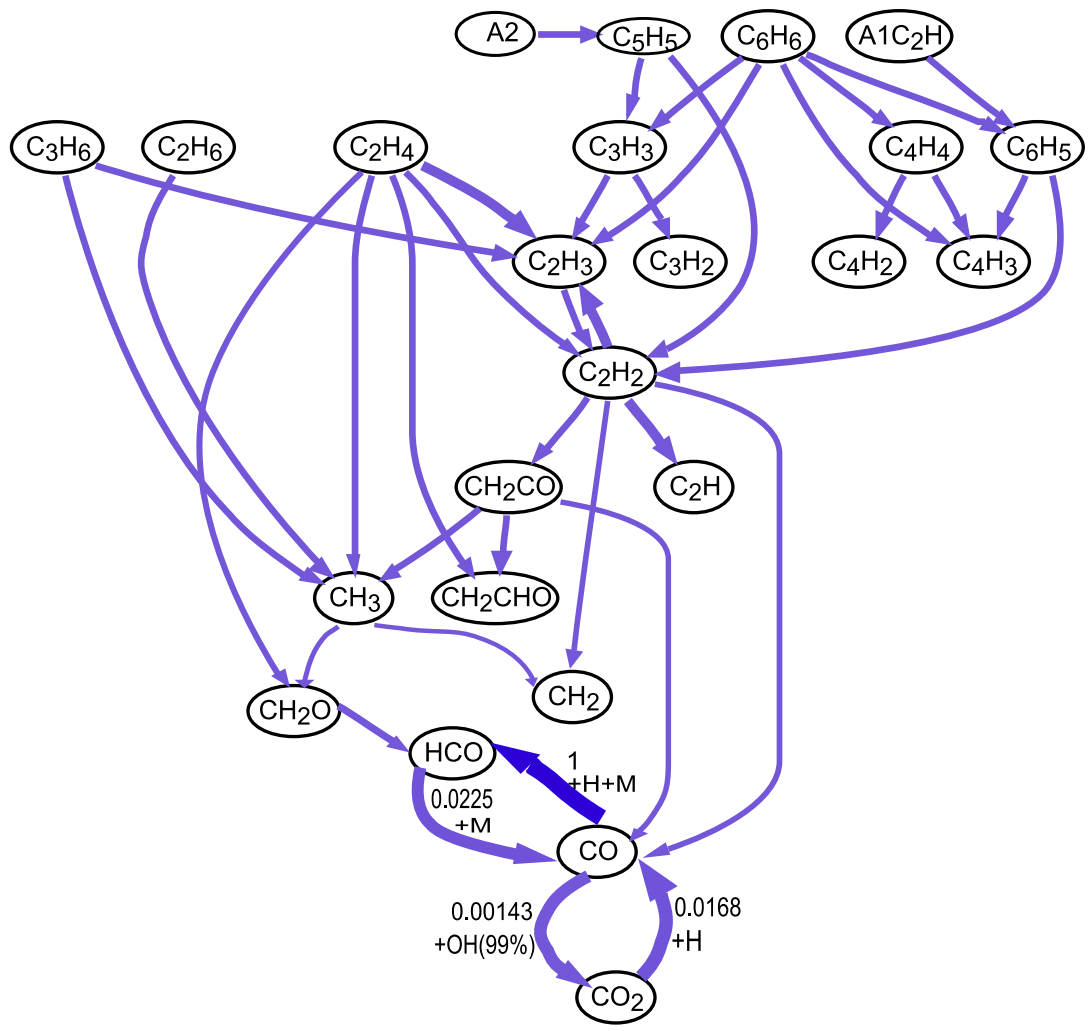

Fig. 8. Combustion reaction paths in the oxygen-rich zone of flame.

of methane/air flames were observed to stay almost constant from 10 to $100 \mathrm{MPa}$ [7], and the visible flame height of $n$-heptane/air flames stayed constant (about $9.5 \mathrm{~mm}$ ) at 0.1-1 MPa [11].

For the circular fuel nozzle with the approximation of the flame height of a buoyancy-dominated laminar coflow diffusion flame, Roper [37] proposed a formulation to predict the flame height as follows:

$H \propto \frac{Q / T_{f}^{0.67}}{D \ln (1+1 / S)} \propto \frac{1}{P T_{f}^{0.67}} \frac{v A}{D \ln (1+1 / S)}$

where $Q$ is the volumetric flow rate of fuel under standard state, $T_{f}$ is the mean flame temperature, $S$ is the molar stoichiometric ratio of oxidizer to fuel, $D$ is the diffusion coefficient at ambient temperature, $v$ is the fuel exit velocity at operating pressure, and $A$ is the fuel nozzle exit area. $S$ is equal to 11 for $n$-heptane/oxygen. It is assured that $D$ is inversely proportional to $P$, and the height of the diffusion flame is independent of the pressure. The experiments of methane/ air and $n$-heptane/air coflow laminar flames performed by Gülder et al. [7,11] validated that the Roper's formulation was valid for high-pressure hydrocarbon/air flame. However, the combustion conditions of high-pressure hydrocarbon/oxygen laminar diffusion flames are different from that of hydrocarbon/air flames [1], the flame heights no longer keep a constant with increasing pressure, and the Roper's formulation is not expected for the prediction of $n$-heptane/oxygen flame height. Gülder and coworkers [7] argued that one of the main reasons was the higher temperature of hydrocarbon/oxygen flames than that of hydrocarbon/air flames (see Fig. 9), and the other reason could be the mass diffusivity's variation with pressure. When the reduced pressure $P_{r}$, the ratio of actual pressure to the critical pressure of the gas, exceeds about 0.5 , the mass diffusivity's inverse dependence on pressure starts deviating from the inverse relationship [1,33], and the product of pressure and diffusivity no longer keeps a constant but starts decreasing with increasing pressure. The critical pressure of $n$-heptane is $2.7089 \mathrm{MPa}$, the reduced pressure, $P_{r}$, is larger than 0.5 when combustion pressure is $2 \mathrm{MPa}$ in the study. It seems that the decrease in the $n$-heptane/oxygen flame height with pressure could be due to 


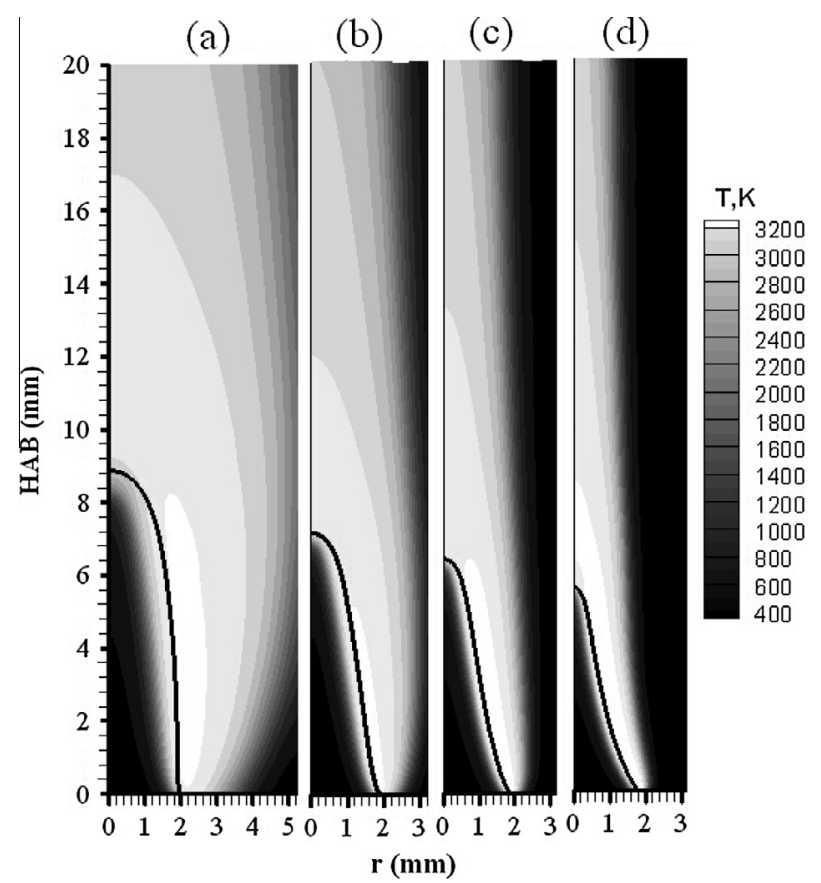

Fig. 9. Effects of pressure on temperature distribution and flame surface (black curves). (a) $0.1 \mathrm{MPa}$, peak: $2848 \mathrm{~K}$; (b) $0.5 \mathrm{MPa}$, peak: $3069 \mathrm{~K}$; (c) $1 \mathrm{MPa}$, peak: $3151 \mathrm{~K}$; and (d) $2 \mathrm{MPa}$, peak: $3221 \mathrm{~K}$

the combined effects of the relatively higher flame temperatures and higher mass diffusivities as well as high oxygen concentration leading to higher oxidation rate of soot.

\subsection{Effect of pressure soot distribution}

Fig. 10 shows the variations of the soot volume fraction distributions with increasing pressure from 0.1 to $2 \mathrm{MPa}$. The results indicate that with increasing pressure, soot formation location shifts down, the peak value of soot concentration increases from 0.045 to $19.518 \mathrm{ppm}$, the high concentration of soot distribution starts to appear the annular band, and the peak soot concentration occurs on the flame sides. With the increase of pressure, flame surface become narrower (see Fig. 9), the large gradient of tempera-

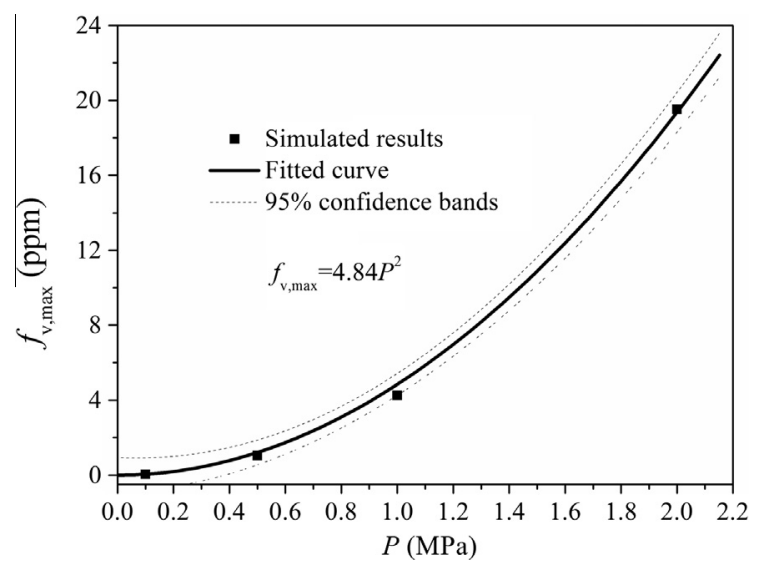

Fig. 11. Maximum soot volume concentration as a function of pressure

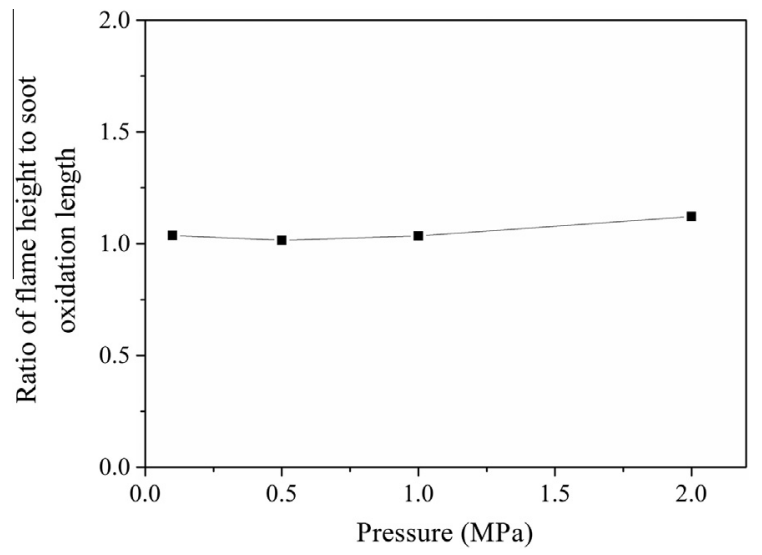

Fig. 12. The ratio of flame height to soot oxidation length as a function of pressure.

ture near the burner exit enhances the thermal diffusion from the hot regions towards center, then this increases high fuel pyrolysis rate and accelerates soot nucleation and growth as well as soot formation.

The maximum soot volume fraction $\left(f_{v \text {,max }}\right)$ increases with pressure as $f_{v, \text { max }} \propto P^{2}$ at 0.1-2 MPa (see Fig. 11). As known from Figs. 9

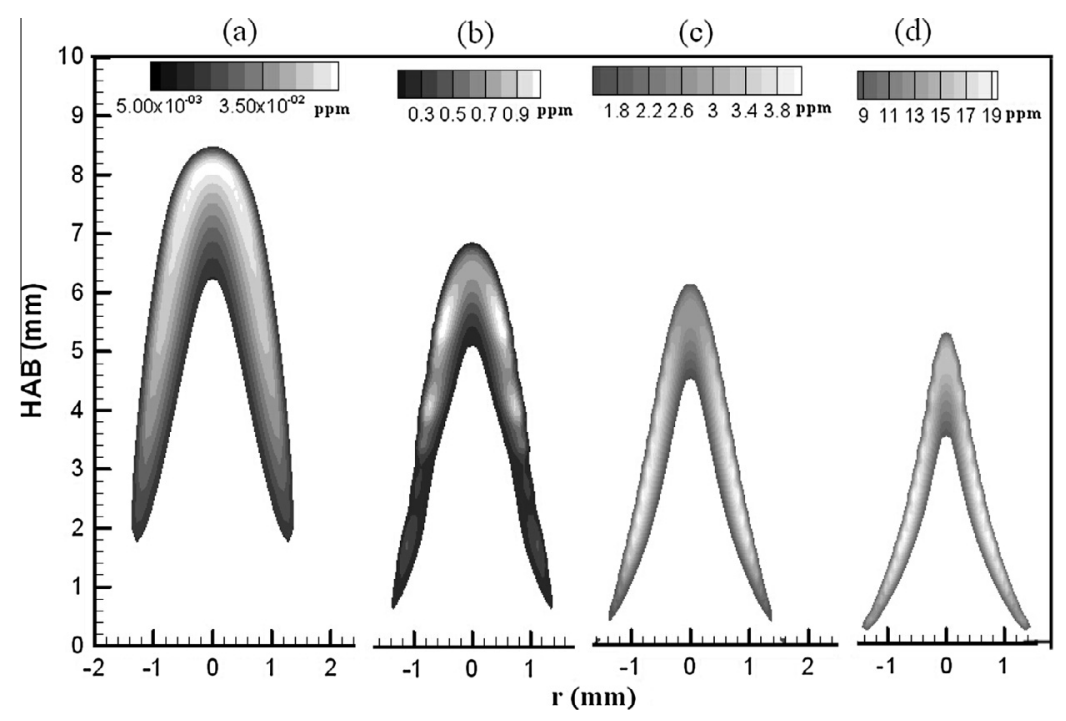

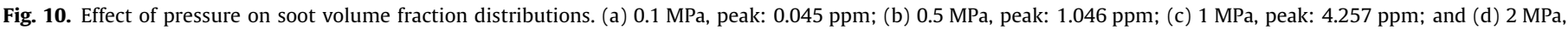
peak: $19.518 \mathrm{ppm}$ 
and 10 , for $n$-heptane/oxygen flames, the ratio of flame height to soot oxidation length (the distance between burner exit and the location of soot complete oxidization along flame centerline) is close to unity (1.037-1.121), as shown in Fig. 12, which is similar to hydrocarbon/air coflow flames [38].

\section{Conclusions}

The skeletal reaction mechanism of $n$-heptane combustion is developed by principal component analysis (PCA), and it is validated by the experimental results of ignition delay time and the species distributions (PAHs and soot). The $n$-heptane/oxygen coflow laminar flame is simulated with the skeletal reaction mechanism. The reaction paths of each reaction zone in flame are presented. The simulation results indicate that (1) the $n$-heptane/ oxygen flame height decreases from 8.8 to $5.6 \mathrm{~mm}$ with the increase of the pressure from 0.1 to $2 \mathrm{MPa},(2)$ the flame height variation of hydrocarbon/oxygen with pressure is different from that of hydrocarbon/air flame, and (3) the Roper's formulation is not expected for the prediction of the $n$-heptane/oxygen flame height. The maximum soot volume fraction increases with pressure as $f_{v, \max } \propto P^{2}$ at $0.1-2 \mathrm{MPa}$. The ratio of flame height to the soot oxidation length of $n$-heptane/oxygen flames is close to unity (1.037-1.121), which is similar to hydrocarbon/air flames.

\section{Acknowledgement}

Financial support by National Natural Science Foundation of China (Nos. 51376189, 91130028) is acknowledged.

\section{Appendix A. Supplementary material}

Supplementary data associated with this article can be found, in the online version, at http://dx.doi.org/10.1016/j.fuel.2015.09.013.

\section{References}

[1] Joo HI, Gülder öL. Soot formation and temperature structure in small methaneoxygen diffusion flames at subcritical and supercritical pressures. Combust Flame 2010:157:1194-201.

[2] Flower WL, Bowman CT. Soot production in axisymmetric laminar diffusion flames at pressures from one to ten atmospheres. Proc Combust Inst $1988 ; 21: 1115-24$.

[3] Lee W, Na YD. Soot study in laminar diffusion flames at elevated pressure using two-color pyrometry and Abel inversion. JSME Int J Ser B 2000;43:550-5.

[4] Liu F, Thomson KA, Guo H, Smallwood GJ. Numerical and experimental study of an axisymmetric coflow laminar methane-air diffusion flame at pressures between 5 and 40 atmospheres. Combust Flame 2006;146:456-71.

[5] Lefebvre AH. Gas turbine combustion. 2nd ed. Ann Arbor, MI: Taylor and Francis; 1998.

[6] Sutton GP. History of liquid propellant rocket engines. Reston, Virginia: American Institute of Aeronautics and Astronautics; 2006.

[7] Joo HI, Gülder öL. Soot formation and temperature field structure in coflow laminar methane-air diffusion flames at pressures from 10 to $60 \mathrm{~atm}$. Proc Comb Inst 2009;32:769-75.

[8] McCrain LL, Roberts WL. Measurements of the soot volume field in laminar diffusion flames at elevated pressures. Combust Flame 2005;140:60-9.

[9] Thomson KA, Gülder öL, Weckman EJ, Fraser RA, Smallwood GJ, Snelling DR. Soot concentration and temperature measurements in co-annular, nonpremixed $\mathrm{CH}_{4}$ /air laminar flames at pressures up to $4 \mathrm{MPa}$. Combust Flame 2005;140:222-32.
[10] Bento DS, Thomson KA, Gülder ÖL. Soot formation and temperature field structure in laminar propane-air diffusion flames at elevated pressures. Combust Flame 2006;145:765-78.

[11] Karatas AK, Intasopa G, Gülder ÖL. Sooting behaviour of $n$-heptane laminar diffusion flames at high pressures. Combust Flame 2013;160:1650-6.

[12] Lee KO, Megaridis CM, Zelepouga S, Savaliev AV, Kennedy LA, Charon O, et al. Soot formation effects of oxygen concentration in the oxidizer stream of laminar coannular nonpremixed methane/air flames. Combust Flame 2000;121:323-33.

[13] Bakali AE, Delfau JL, Vovelle C. Measurement of soot volume fraction and gaseous species concentrations in premixed $n$-heptane and iso-octane flames. Chim Phys 1997:94:1659-73.

[14] Inal F, Senkan SM. Effects of equivalence ratio on species and soot concentrations in premixed $n$-heptane flames. Combust Flame 2002;131: $16-28$.

[15] Agafonov GL, Naydenova I, Vlasov P, Warnatz J. Detailed kinetic modeling of soot formation in shock tube pyrolysis and oxidation of toluene and $n$ heptane. Proc Comb Inst 2007;31:575-83.

[16] Anna AD, Alfe M, Apicella B, Tregrossi A, Ciajolo A. Effect of fuel/air ratio and aromaticity on sooting behavior of premixed heptane flames. Energy Fuels 2007;21:2655-62.

[17] Karatas AE, Gülder ÖL. Soot formation in high pressure laminar diffusion flames. Prog Energy Combust Sci 2012;38:818-45.

[18] Wang H, Reitz RD, Yao M, Yang B, Jiao Q, Qiu L. Development of an n-heptanen-butanol-PAH mechanism and its application for combustion and soot prediction. Combust Flame 2013;160:504-19.

[19] Lu T, Law CK. A directed relation graph method for mechanism reduction. Proc Comb Inst 2005;30:1333-41.

[20] Pepiot-Desjardins P, Pitsch H. An efficient error-propagation-based reduction method for large chemical kinetic mechanisms. Combust Flame 2008;154: 67-81.

[21] Turányi T, Bérces T, Vajda S. Reaction rate analysis of complex kinetic systems Int J Chem Kinet 1989;21:83-99.

[22] Nagy T, Turányi T. Reduction of very large reaction mechanisms using methods based on simulation error minimization. Combust Flame 2009;156:417-28.

[23] Brown NJ, Li G, Koszykowski ML. Mechanism reduction via principal component analysis. Int J Chem Kinet 1977;29:393-414.

[24] Vajda S, Valko P, Turanyi T. Principal component analysis of kinetic models. Int J Chem Kinet 1985;17:55-81.

[25] Hartmann M, Gushterova I, Fikri M, Schulz C. Auto-ignition of toluene-doped n-heptane and iso-octane/air mixtures: high-pressure shock-tube experiments and kinetics modeling. Combust Flame 2011;158:172-8.

[26] Oliveira MH, Olofsson NE, Johnsson J, Bladh H, Lantz A. Soot, PAH and $\mathrm{OH}$ measurements in vaporized liquid fuel flames. Fuel 2013;112:145-52.

[27] Oliveira A, Luijten MH, Goey CCM. Soot measurements in laminar flames of gaseous and (prevaporized) liquid fuels. In: Proceedings of the 4th ECM. Vienna, Austria; 2009. p. 1-6.

[28] Callahan MP, Abo-Riziq A, Crews B, Grace L. Isomer discrimination of polycyclic aromatic hydrocarbons in the Murchison meteorite by resonant ionization. Spectrochim Acta A Mol Biomol Spectrosc 2008;71:1492-5.

[29] Hall RJ, Smoke MD, Colket MB. Physical and chemic aspects of combustion. Gordon and Breach; 1997.

[30] Fluent A. 12.0 Theory guide. Ansys Inc.; 2009.

[31] Cuoci A, Frassoldati A, Faravelli T, Ranzi E. A computational tool for the detailed kinetic modeling of laminar flame: application to $\mathrm{C}_{2} \mathrm{H}_{2} / \mathrm{CH}_{4}$ coflow flames. Combust Flame 2013;160:870-86.

[32] Barlow RS, Karpetis AN, Frank JH, Chen JY. Scalar profiles and NO formation in laminar opposed-flow partially premixed methane/air flames. Combust Flame 2001;127:2102-18.

[33] Reid RC, Prausnitz JM, Polling BE. The properties of liquids and gases. 4th ed. New York: McGraw Hill; 1987.

[34] Goodwin DG. Cantera user's guide. California Institute of Technology; 2001.

[35] Mawid MA, Sekar B. Development of a detailed JP-8/Jet-A chemical kinetic mechanism for high pressure conditions in gas turbine combustors. ASME Turbo Expo 2006: Power for Land, Sea, Barcelona, Spain; 2006.

[36] Joo HI. Soot formation in non-premixed laminar flames at subcritical and supercritical pressure. University of Toronto; 2010.

[37] Roper FG. The prediction of laminar jet diffusion flame sizes: Part I. Theoretical model. Combust Flame 1977;29:219-26.

[38] Roper FG, Smith C, Cunningham AC. The prediction of laminar jet diffusion flame sizes: Part II. Experimental verification. Combust Flame 1977;29: 227-34. 